\title{
DE INFRAESTRUCTURA A PAISAJE La carretera austral como motor de resignificación
}

\author{
FULVIO ROSSETTI \\ Profesor Asistente Adjunto \\ Escuela de Arquitectura, \\ Pontificia Universidad Católica de Chile, \\ Santiago, Chile
}

Palabras clave

Transporte

Renaturalización

Patagonia

Augusto Pinochet

Soberanía
Habitualmente entendemos a las infraestructuras en términos de su funcionalidad, es decir, como medios al servicio de otra cosa o bien como soportes de una actividad. Sin embargo, tal como lo demuestra este texto, ellas son más versátiles de lo que parecen: también pueden crear nuevos significados y detonar visiones distintas que incluso contradigan a las que les dieron origen.

$\mathrm{E}$ 1 cerro Castillo, nevado y enmarcado por las hojas rojizas de un bosque caduco (FIG. I), protagoniza la portada del libro Carretera Austral, el camino más espectacular de Sudamérica (A A.vv., 2012). Este coffee-table book fue patrocinado por movimientos ecologistas que, liderados por figuras como Douglas Tompkins, han posicionado la idea de Aysén y la Patagonia como una inmensa reserva virgen a preservar. La foto integra una serie de publicaciones que los mismos actores difundieron en Patagonia chilena iSin represas! (A A.vv., 2007), una intensa campaña mediática en contra del proyecto de generación hidroeléctrica HidroAysén. Buscaban, en cambio, integrar al sistema de parques nacionales una serie de terrenos que el propio Tompkins fue adquiriendo desde los '9o para su 'rewilding', revirtiendo áreas ganaderas a su estado de naturaleza virgen y convirtiendo los tramos de la red vial que las atravesaban en rutas escénicas.

En este contexto, la imagen sublime del cerro Castillo - parte de las bellezas admirables desde la carretera expresaba una idea territorial más amplia: adelantaba 


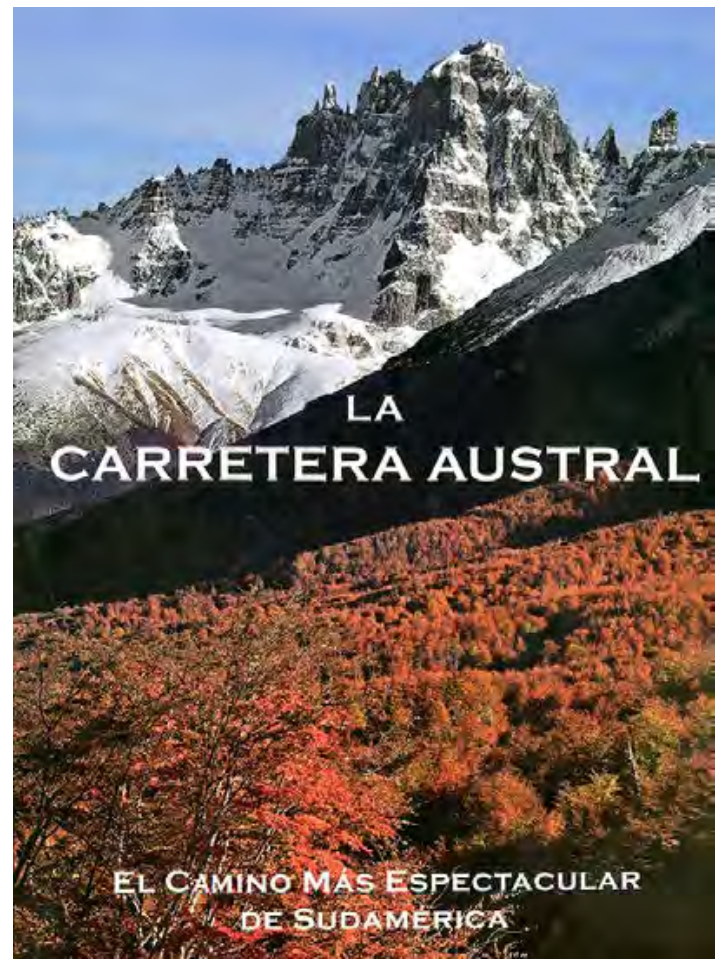

FIG 1 Cerro Castillo en la portada del libro La Carretera Austral. El camino más espectacular de Sudamérica. / Cerro Castillo on the cover of the book Carretera Austral. The most spectacular road in South America. Fuente / Source: Editoria Ocho Libros, 2012

la reciente constitución de la red de Parques de la Patagonia que, conectados por una carretera y una ruta naval, fue institucionalizada por la presidenta Michelle Bachelet en enero de 20I8. La sucesión de parques (FIG.2) fue creada en gran medida integrando las reservas de Tompkins al sistema de áreas protegidas del Estado. Así, este proyecto cristalizaba una imagen que se construyó a través de la lucha de los movimientos ecologistas y el alineamiento de algunos gobiernos de centroizquierda post dictadura.

La red consolida la idea de la Patagonia como un territorio a valorar por una supuesta virginidad e implica mantenerlo al margen del desarrollo. Esta idea, como imagen de belleza, se difundió intencionadamente con un discurso que destacaba la posibilidad de gozar, por vía terrestre, «[d]el camino más espectacular de Sudamérica» y, por vía marítima, de la «ruta escénica de los glaciares más impresionante de Chile, y (...) del mundo» ${ }^{1}$. Si bien este discurso afirmaba que la carretera energética de HidroAysén cortaría al país en dos, se daba a entender que, como soporte para percepción escénica y continuidad ecológica, esta misma ruta tendría la capacidad de unirlo.

En otra portada más antigua, mirando hacia arriba, de manos cruzadas y con una pose segura, el general Pinochet protagonizó un número extraordinario de la Revista de la Asociación Latinoamericana de Integración de I98I (FIG.3). Inmortalizando al dictador con un traje y corbata celestes, la portada celebraba la próxima inauguración del primer tramo de la misma carretera que hoy es aplaudida por los ecologistas más radicales, aunque por razones diametralmente opuestas.

Como la obra estrella entre una serie de operaciones de propaganda, la inauguración de la «Carretera 
FIG 2 Parques Nacionales y Reservas Forestales en la Patagonia de Argentina y Chile, 1978. / National Parks and Reserves at Patagonia in Argentina and Chile, 1978.

Fuente / Source:

Elaboración propia

The autor

\section{LEYENDA / LEGEND}

Reservas Forestales / Reserves

a. Llanquihue (1912)

b. Lago Palena (1965)

c. Lago Ensueño (1968)

d. Puyuhuapi (1969)

e. Puerto Cisnes (1969)

f. Los Cuervos (s.f.)

g. Lago Carlota (1965)

h. Las Guaitecas (1938)

i. Isla Magdalena

I. Los Cuervos (s.f.)

m. Las Quemas (s.f.)

n. Río Norte (s.f.)

o. Mano Negra (s.f.)

p. Isla Ester (1964)

q. Los Leones (s.f.)

r. Coyhaique (1948)

s. Cerro Castillo (1970)

t. Taitao (1969)

u. Lago Jeinimeni (1967)

v. Lago General Carrera (1967)

w. Lago Cochrane (1967)

x. Río Pascua (1974)

y. Alacalufes (1969)

z. Magallanes (1932)

Parques Nacionales / National Parks Argentina

1. Nahuel Huapi (ex Del Sud 1922)

2. Lago Puelo (1937)

3. Los Alerces (1937)

4. Perito Moreno (1937)

5. Los Glaciares (1937)

Chile

6. Puyehue (1941)

7. Vicente Pérez Rosales (1926)

8. Lago Rossellot (1968)

9. Lago Las Torres (1969)

10. Isla Guamblin (1937)

11. Cinco Hermanas (1970)

12. Puerto Chacabuco (1970)

13. Río Simpson (1967)

14. Dos Lagunas (1967)

15. Los Huemules (1967)

16. Quitralco (1967)

17. Bahía Erasmo (s.f.)

18. Laguna San Rafael (1959)

19. El Guyaneco (1967)

20. Bernardo O'Higgins (1969)

21. Torres del Paine (1959)

22. Pali Aike (1970)

23. Alberto de Agostini (1965)

24. Cabo de Hornos (1945)

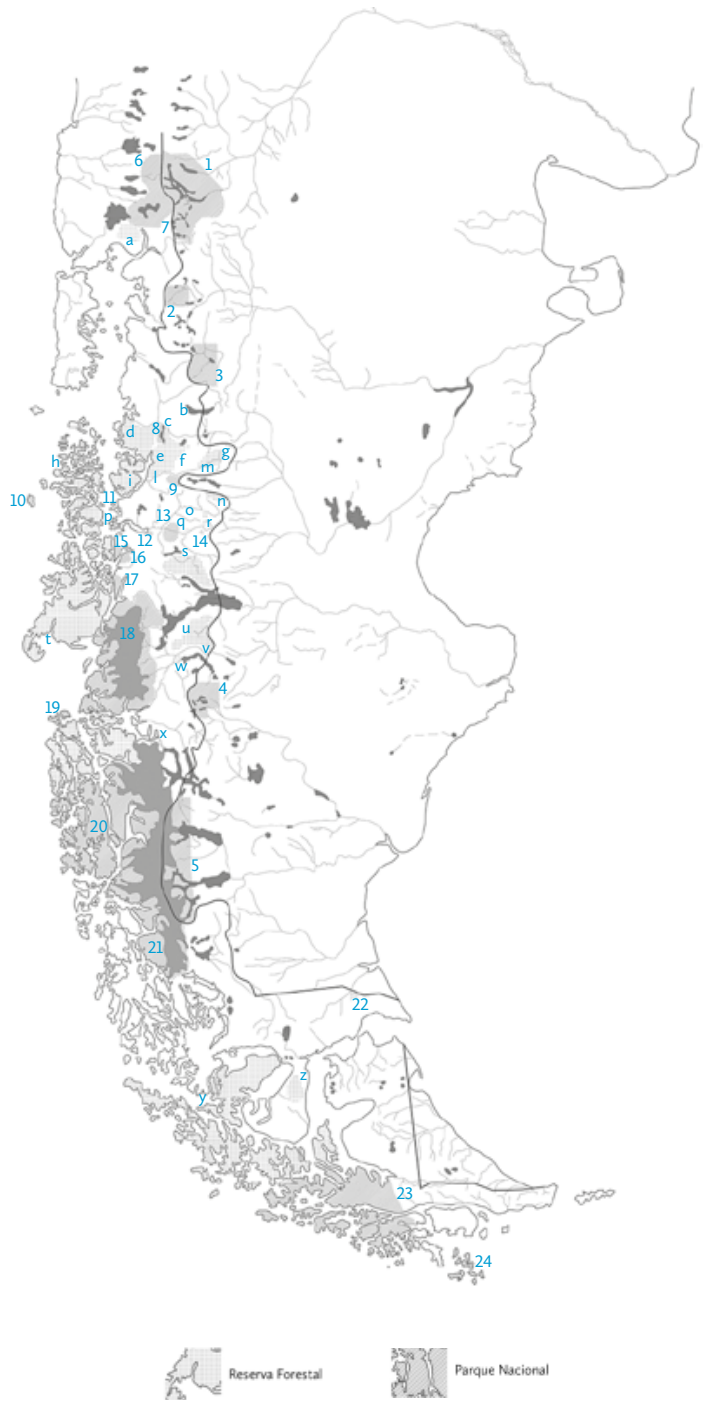

Longitudinal Austral Presidente Pinochet» implicaba un mensaje distinto: no era una ruta para el disfrute visual (aunque la belleza no se despreciaba), sino una obra de infraestructura de importancia estratégica, cuyos efectos productivos y transformadores del territorio irían en directo beneficio de los pobladores de la región y el país. La portada evocaba la unidad del país con un discurso que, estructurado alrededor de la necesidad de su homogeneización productiva, concebía la virginidad y el despoblamiento del territorio austral como un mal a revertir a través del poblamiento y un sistema de comunicaciones adecuado. Asociando la obra con el rostro de un personaje formado en el mundo académico militar del Chile de la segunda mitad del siglo $\mathrm{xx}^{2}$, la portada sugiere además que las razones detrás de la carretera son geopolíticas. Así, las ideas que hoy rodean a esta infraestructura sólo vienen a culminar un proceso de resignificación cultural que requiere ser estudiado. Porque detrás de la poco creíble imagen virginal de un territorio que fue también escenario de distintas luchas y conflictos, está la riqueza de una historia que tiende a olvidarse. 
La carretera austral buscó completar un proceso de integración que empezó a inicios del siglo xx, cuando el laudo arbitral de 1902 trazó de manera relativamente definitiva el límite que separaba la Patagonia chilena de la argentina (espacios que, a excepción de la isla de Chiloé, mantuvieron su estado indígena hasta la época republicana). Tras del laudo se buscó 'chilenizar' este territorio entre Punta Arenas y Puerto Montt - polos de colonización ya consolidados - iniciando un proceso no exento de problemas, conflictos y tensiones fronterizas originadas, principalmente, por la permeabilidad que el límite presenta en este tramo.

Pero la accidentada geografía dificultó la integración de este territorio. Los cordones transversales que van de oriente a poniente (FIG.4) obstaculizaron por mucho tiempo la posibilidad de ejecutar vías que extendieran hacia el sur las rutas terrestres como la carretera Panamericana o el ferrocarril longitudinal. A la vez, como las zonas más planas se ubican en áreas alejadas de la costa, los procesos de poblamiento ocurrieron en sectores como las pampas limítrofes. Estos territorios eran difíciles de integrar al resto de Chile pero estaban muy bien conectados con la Patagonia argentina y sus redes de infraestructura. Los caminos argentinos, la ruta 40 y puertos como Comodoro Rivadavia, fueron infraestructuras indispensables no sólo para el desarrollo trasandino, sino también para la supervivencia de los pobladores de las pampas chilenas. Esta vinculación con una región extranjera, junto al retraso en la construcción de vías de comunicación interna, delineó una situación de dependencia de la que derivaron las mayores tensiones para su incorporación a la vida chilena.

Pero dicha incorporación no refería sólo a la creación de infraestructuras en una geografía accidentada, sino también a la necesidad de entender el rol que este territorio aún incógnito debería jugar en el país. La incorporación se presentó como un discurso cultural vinculado a - y condicionado por - las problemáticas de integración infraestructural.

Antes de la carretera austral, la articulación entre atribución de significados y problemas de comunicación se percibió en los primeros intentos de nacionalización mediante obras viales, fluviales y aéreas. Un intento inicial fue la carretera transversal realizada en el primer gobierno de Carlos Ibáñez del Campo y celebrada por las fotografías que Robert Gerstmann publicó en su libro sobre Chile en I932 (Gerstmann, I932). En ellas se enfatizaba el avance de la soberanía, celebrando la quema de bosques necesarias para la ejecución de la obra vial (F IG.5), junto a los riesgos implícitos por la presencia de gauchos y británicos en tierra chilena. Otro caso es el proyecto turístico asociado al transporte de cruceros y la construcción del hotel de la laguna San Rafael a fines de los años 30. La primera difusión masiva del «paroxismo de extática belleza» (Ried, I939) de estos paisajes en la revista En Viaje, evidenciaba la voluntad de poblar la costa; así se establecería un nuevo equilibrio geopolítico que afirmara la soberanía y asegurara la independencia de los pobladores chilenos a

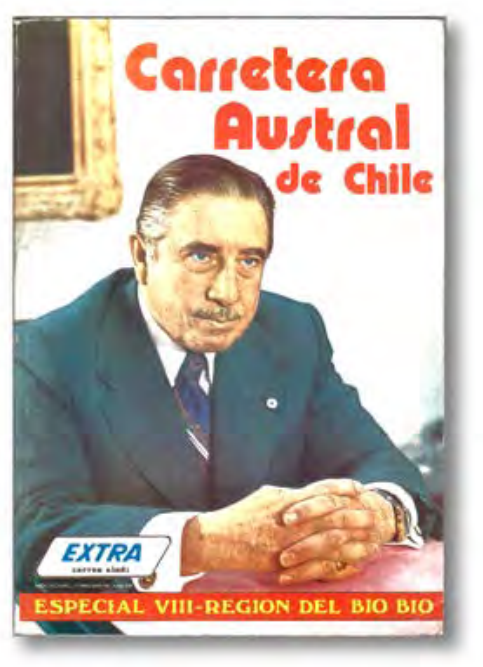

FIG 3 Portada de la Revista de la Asociación Latinoamericana de Integración. Edición Extraordinaria, 1981. / Cover of the Association for Latin American Integration's magazine, 1981 Extraordinary Issue. Fuente / Source: Asociación Latinoamericana de Integración (ALADI) 
través del mar interior, gracias a la nacionalización de los transportes marítimos y la construcción del canal del istmo de Ofqui.

Pero tras el fracaso de estos proyectos en el istmo de Ofqui a fines de los años $30^{3}$, las infraestructuras aéreas tomaron el protagonismo. Si en 1946 comenzó a funcionar el primer aeródromo en Balmaceda ${ }^{4}$, a comienzos de los 70 prácticamente cada poblado tenía el suyo (Millar, I994:I25). Así, el transporte aéreo se convirtió en el principal medio de comunicación de la región, y tuvo la misión de redireccionar los flujos comerciales y de personas hacia Chile. Ello, sin embargo, también contribuyó al abandono de la voluntad de colonizar el ambiente marítimo, ya que su integración se hacía innecesaria. A su vez, al conectar las conflictivas pampas fronterizas por vía área, ellas podían mantenerse en su estado primigenio y sus bosques vírgenes podían protegerse como reservas forestales. En ese escenario, no se registraron nuevos intentos de colonización hasta la segunda mitad de los años 80.

En un estado de virginidad - ratificada en 1959 con la delimitación de los parques nacionales de Torres del Paine y Laguna San Rafael - el espacio de archipiélagos, fiordos, canales, costa y hielos continentales se convirtió en una extensa área protegida. A ella se le atribuyó el significado simbólico de un paisaje representativo de la nación y su continuidad hasta el Polo Sur. En este proceso, la avioneta no sólo liberó el ambiente marítimo de la urgencia de su ocupación, sino que resignificó el mar a través de nuevas representaciones, como las

FIG 4 Mapa esquemático topográfico de la Patagonia presentado por Hans Steffen para ilustrar una charla en la Royal Geographical Society en 1900. / Topographical scheme map of Patagonia presented by Hans Steffen to illustrate a conference at the Royal Geographical Society in 1900

Fuente / Source: Ibero-amerikanisches Institut, Berlin (IAI) fotografías que Gerstmann publicó para la nueva edición de su libro de instantáneas de Chile en i959. Las fotos aéreas de glaciares y campos de hielo, realizadas durante los primeros vuelos experimentales de la década del ' 30 , completaban una serie en que a Aysén se le otorgaba el valor de espacio indómito. Estas fotos, a través de las que dicho paisaje se difundió quizás por primera vez de manera integral, anticiparon las posteriores políticas de protección de los recursos naturales. A la vez, ellas representaban una apropiación para nada inocente: durante las reclamaciones chilenas de soberanía sobre la Antártica - fundamentadas en la continuidad natural de sistemas glaciales desde que, supuestamente, no podían sino pertenecer al país - la belleza de los hielos milenarios servía para argumentar el dominio geopolítico.

\section{El valor del mar. La red vial austral} y la era del Pacífico.

Entre los 40 y los 70, el desarrollo del transporte aéreo contribuyó a consolidar la idea de las pampas fronterizas como subregiones de vocación ganadera y las marítimas como espacios a conservar o preservar. Pero el transporte aéreo también contribuyó a la ejecución de la red de rutas terrestres iniciadas en 1976 durante la dictadura de Pinochet. Además de permitir el transporte de materiales y víveres a los campamentos instalados en las selvas durante la construcción, sobrevolar el territorio posibilitó el reconocimiento de zonas accidentadas, desconectadas y boscosas que eran difíciles de alcanzar con otros medios. Así, en I97I

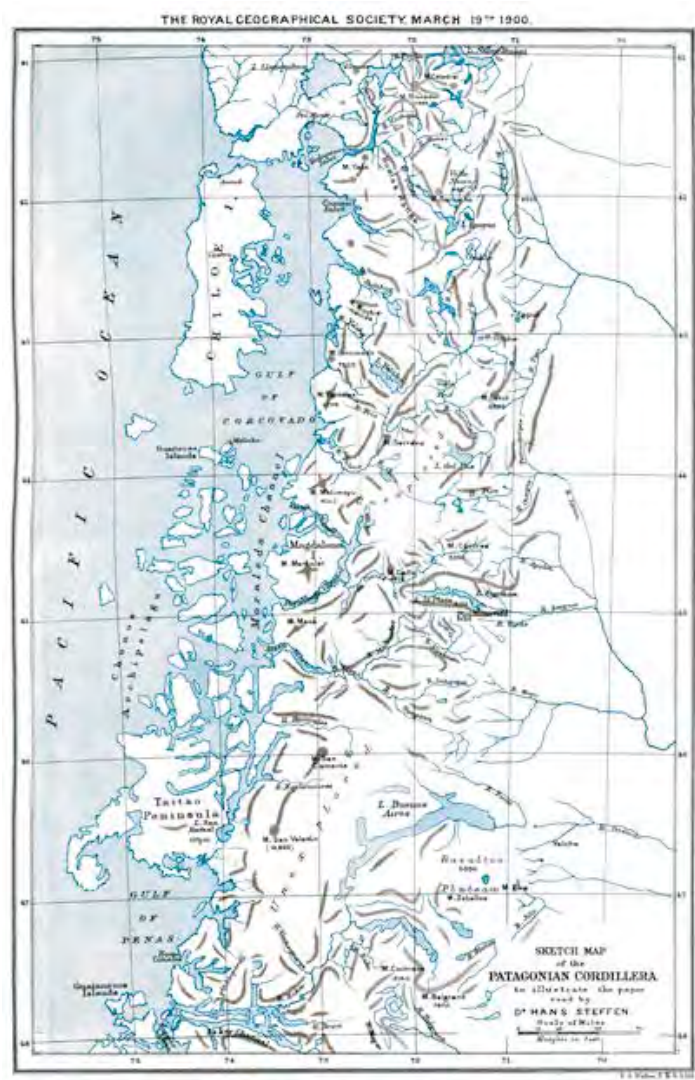




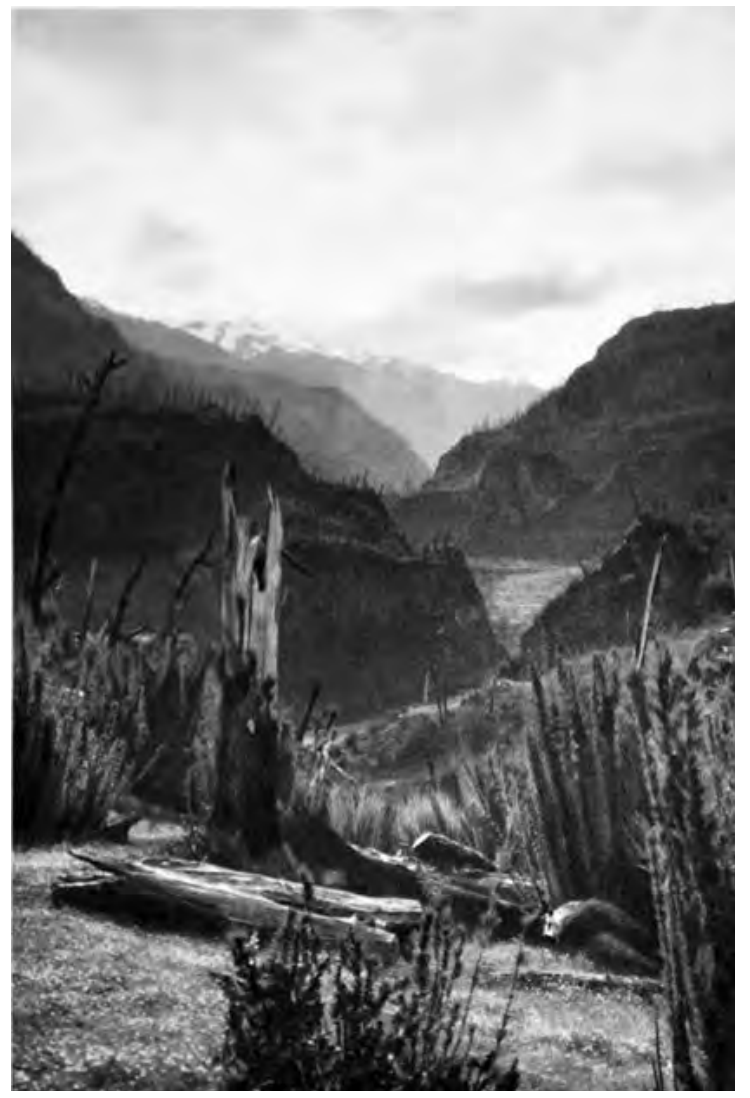

se realizó el primer levantamiento aerofotogramétrico, gracias al cual fue posible dibujar los primeros trazados.

Si bien desde los años 30 se plantearon distintas ideas sobre posibles conexiones terrestres, el trazado siempre fue imaginado con una línea norte-sur y varios caminos secundarios que, a lo largo de los valles transversales, unirían la costa con la troncal y las pampas limítrofes. Para simplificar la tarea, la troncal norte-sur debía trazarse en zigzag, integrando parte de los caminos transversales y atravesando los cordones en las áreas más bajas 5 . La primera etapa se ejecutó entre 1976 y 1982 (FIG. 6), es decir, cuando Argentina también se encontraba bajo dictadura, dando inicio a una política bélica y de disputas territoriales con Chile e Inglaterra por el límite en la Patagonia y la posesión de las islas Malvinas. La posibilidad de un conflicto, el temor a una invasión (Polloni, I982) y el mayor aislamiento que vivieron los poblados fronterizos convencieron a la Junta de Gobierno de la urgencia de la ruta. La obra se inició en base a uno de los trazados planteados en los gobiernos de Frei y Allende, y enfrentó una serie de dificultades técnicas relatadas por la Revista de Caminos: corte de rocas, pendientes marcadas, e incluso la construcción sobre suelos pantanosos o cuerpos de agua (FIG. 7).

La ruta se concibió como un sistema progresivo: primero se construyeron caminos ripiados más angostos que, en una segunda fase, serían ensanchados y pavimentados. El trazado debía ser curvilíneo para reducir los costos que significarían tramos rectos sobre una topografía tan accidentada. Asimismo, para minimizar el tamaño de los puentes, se organizaron transbordos en

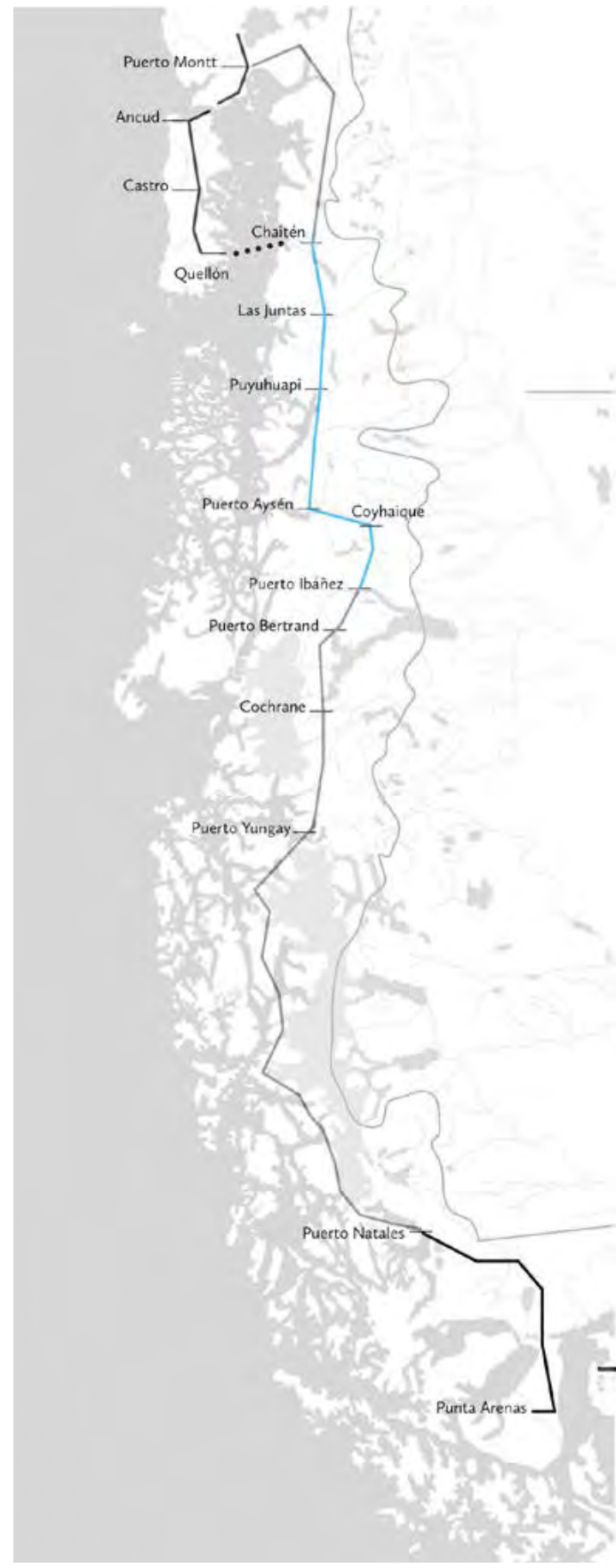

FIG 5 Valle del río Simpson. Bosques quemados para abrir el camino internacional del Gobierno de Ibáñez. Fotografía de Robert Gerstmann. / Simpson River Valley. Forests burned to open Ibáñez Government's international road. Photograph by Robert Gerstmann Fuente / Source: 280 grabados en cobre, 1932

FIG 6 Red vial austral. Trazado esquemático. En azul la continuidad que se concretó alrededor de 1982, en negro los tramos preexistentes, en gris los tramos imaginados para el futuro, en línea punteada el trasbordo entre la Ruta 5 por Chiloé y la ruta continental. / Southern road network. Schematic layout. In blue, continuity achieved circa 1982; in black, pre-existing fragments; in gray, future fragments; in dotted line, the transshipment between Route 5 through Chiloé and the continental route. 
barcazas de empresas particulares o balsas. Articulando las tareas del мо p con el Cuerpo Militar del Trabajo, la Fuerza Aérea, empresas particulares e incluso civiles voluntarios, en pocos años se ejecutó el tramo ripiado norte. El resto quedó para después.

Junto a los avances se buscó impulsar políticas territoriales que activaran los potenciales de la costa. Mientras los cruceros a la laguna San Rafael seguían vigentes, la Junta de Gobierno intentó implementar la producción pesquera de merluza austral (COR FO, I983; Brinck Pisent, 201I) y salmón (Shigeru, 1986). Se elaboraron planes, como la estrategia para el desarrollo del desierto verde (Andrade, I975), estudios para asentamientos en el litoral y planes de colonización que se iniciaron en I983 con la desafectación de la reserva Puyuhuapi y la fundación de la colonia Melimoyu. La carretera añadiría una alternativa terrestre que activara ese ámbito marítimo: como sugería el ingeniero militar Polloni, cercano a Pinochet y a cargo de la colonia antes mencionada, había que «poblar parcialmente el difícil litoral del Pacífico (...) paralelamente con la construcción de las transversales» de la red vial austral (Polloni, I986:I33).

La ejecución de la carretera longitudinal austral y las rutas transversales fue evidentemente catalizada por tensiones limítrofes. Sin embargo, varias publicaciones vinculadas al mundo militar de la época muestran que su interés para la Junta de Gobierno se relacionaba a ambiciones geopolíticas mayores: las pretensiones antárticas que habían surgido ya en los años '4o. Desde entonces, actores como José Domingo Cañas imaginaron el país como una potencia mundial en la 'era del Pacífico', gracias a su ubicación en el hemisferio sur y a su larga costa llegando hasta la península Antártica, reclamada por Chile a partir del gobierno de Pedro Aguirre Cerda. Esto permite explicar por qué, a pesar de ser una ruta terrestre, la red vial fue vista como una forma de activary consolidar el poblamiento de un entorno marítimo con un potencial enorme para afianzar el destino del país. A pesar de las dificultades, la red vial fue el principal vehículo de un utópico ideal mayor: devolver al mar el rol protagónico que había perdido (especialmente durante el gobierno de

FIG 7 Ejemplo de las dificultades encontradas en el trazado y la ejecución de la carretera. Sample of the difficulties encountered in the road's layout and execution. Fuente / Source: Revista de Caminos, 1982.
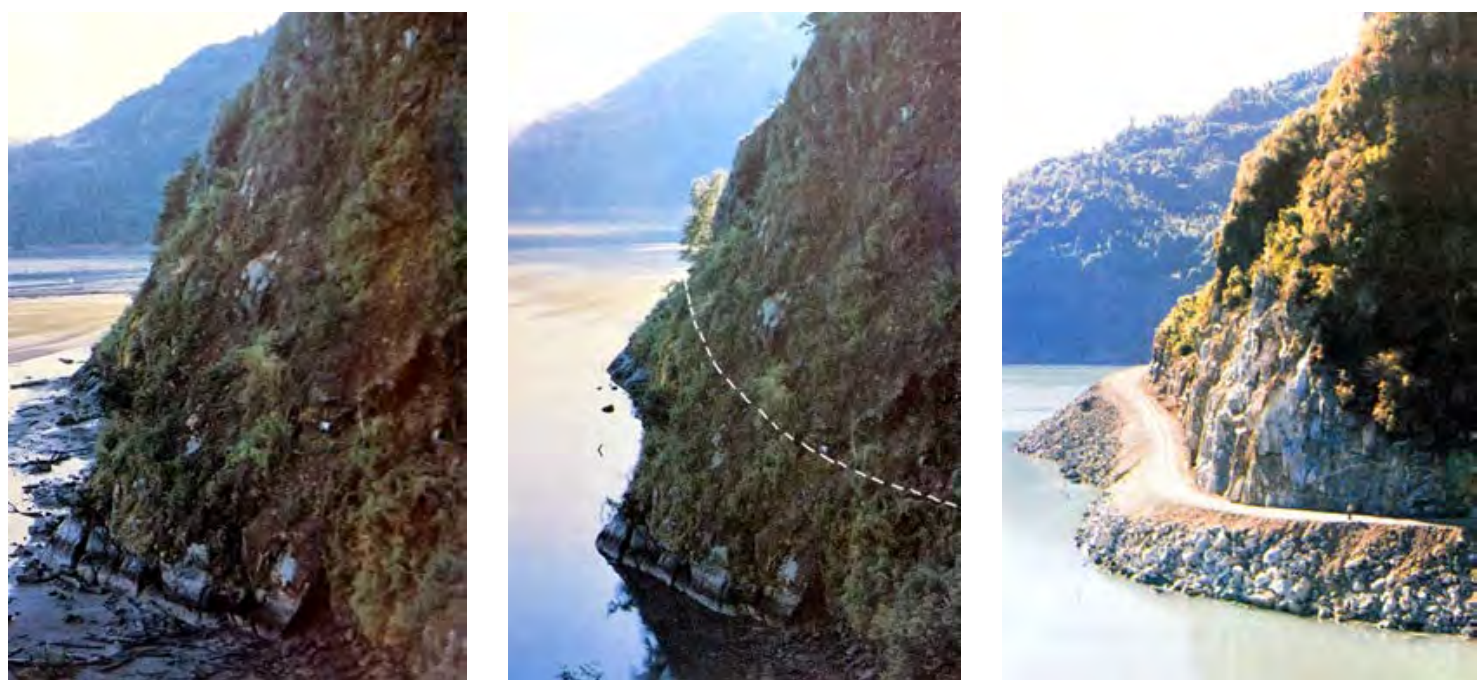
Frei Montalva). Se intentaba demostrar que la costa, los archipiélagos y los fiordos no eran espacios improductivos de por sí, sino que podían ser habitados si existía la voluntad de crear las condiciones para que ello sucediera.

De solución geopolítica a posicionamiento geoeconómico. Un nuevo paisaje.

El mayor impacto cultural que tuvo la carretera Austral se registró gracias a la fotografía y la difusión masiva del paisaje atravesado por la obra. A partir de I982, la inauguración de su primer tramo fue celebrada por distintas publicaciones (Munro, I982; Munro, I989; SERNATUR, I987), incluyendo las imágenes de George Munro, sobrino de Pinochet. Junto con endulzar la figura del General a través de su obra estrella, estas publicaciones celebraban la afirmación de la soberanía, la trasformación de un territorio indómito, su infraestructuralización y el acercamiento de pobladores que, hasta entonces, estaban aislados de la vida nacional (FIG. 8).

Pero además, aunque tímidamente, estas publicaciones empezaban a cuestionar hasta dónde debiese llegar el desarrollo. Las laderas de bosques quemados, (FIG. 9) inmortalizados por Munro en Los Ecos del Silencio: Carretera Austral, pertenecían a una serie de paisajes que no celebraban el avance de la nación por sobre selvas indómitas, sino que denunciaban el daño ecosistémico que estas sufrieron a causa de una colonización devastadora. Es decir, si las tensiones internacionales catalizaron un proyecto integrador que se concretaría con la carretera austral, esta, a su vez, gatilló una nueva imagen del paisaje centro-patagónico que comenzaba a cuestionar el ideario desarrollista bajo el cual había sido imaginado durante años.

Más allá de la simple propaganda, la apreciación del paisaje posibilitada por este proyecto, presentaba a la región como soporte para la activación productiva de una frontera abierta a la nación, o bien como parte de una experiencia estética superlativa que, eventualmente, requeriría de la preservación de su única y hermosa virginidad natural. En otras palabras, la carretera había gatillado el cuestionamiento acerca del rol de la Patagonia en el país, presentando 'lo austral' bajo la misma dicotomía que se podría apreciar en el Pabellón de Chile en la Exposición Iberoamericana de I992: un país empresarial, rico en recursos naturales a explotar y, a la vez, un paraje remoto con sublimes paisajes virginales.

Esta segunda imagen - cristalizada en la instantánea del cerro Castillo - parece haber prevalecido por sobre la visión productivista implícita en el retrato de Pinochet en la portada de la Revista de la Asociación Latinoamericana de Integración. Tras la vuelta a la democracia y con la alineación de los gobiernos de centroizquierda con la lucha ecologista y su argumento de rewilding, el proyecto de integración austral cambió. Así, se resignificó a Aysén como frontera permanente y metonimia de una renovada idea de país.

De última frontera a frontera permanente En la incorporación de Aysén a la vida nacional, las infraestructuras de comunicación tuvieron un rol 

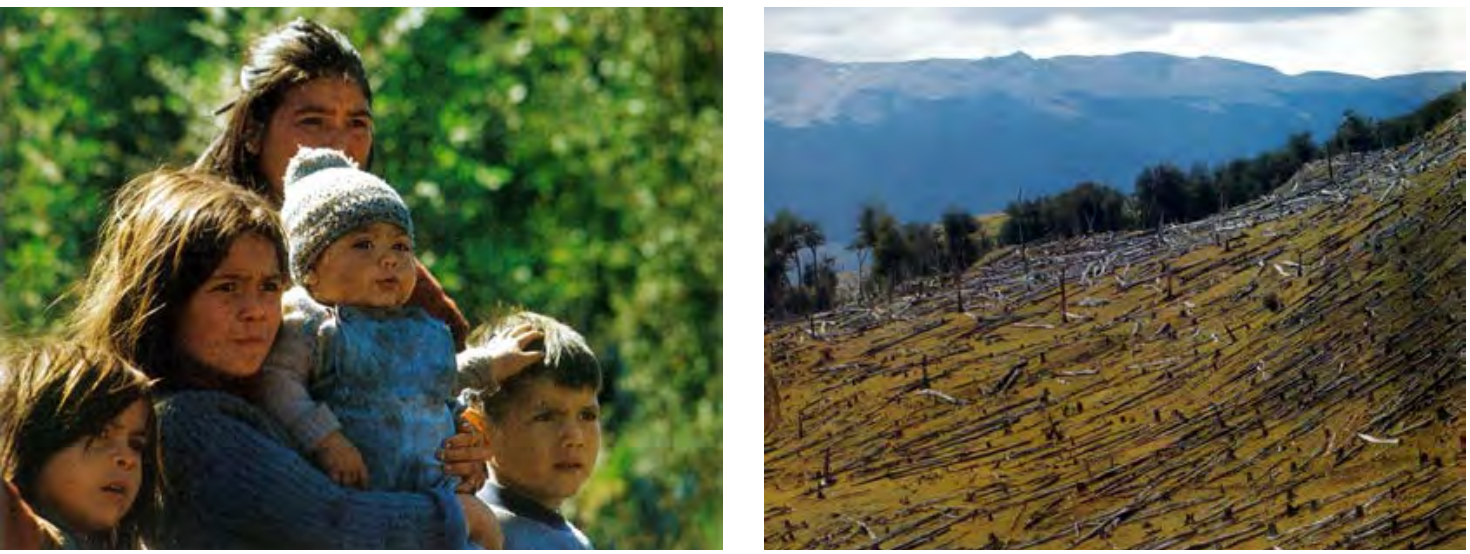

FIG 8 Pobladores de Aysén fotografiados por George Munro. / Aysén settlers photographed by George Munro.

Fuente / Source: Carretera Austral, integración de Chile, 1982

FIG 9 Ladera de troncos quemados fotografiados por George Munro. / Hillside burnt logs photographed by George Munro.

Fuente / Source: Carretera Austral: los ecos del silencio, 1989 protagónico a la hora de atribuirle un nuevo significado a la región. El abandono de Hydroaysén y su carretera energética, la aprobación de la red de parques patagónicos y el entendimiento de la continuidad longitudinal como ruta escénica, parecen haber consolidado un imaginario proclive a la preservación de sus amplias zonas relativamente vírgenes. Como hemos visto, la historia de esta articulación es larga, y ha pasado por distintas etapas, de las cuales la vinculación de la carretera austral con la apreciación escénica - que terminó definiéndola como motor de la defensa ecologista - es quizás la más significativa. De hecho, el proceso cultural que esta infraestructura gatilló es radical, no sólo porque el cambio de significados que contribuyó a ratificar fue el más tajante de la historia de la región, sino porque fue capaz de resignificar a la obra misma, afirmándola como dispositivo visual y no como multiplicador productivo.

Antes de esta resignificación, infraestructuras como el canal de Ofqui, los aeródromos regionales o la misma carretera Austral fueron concebidas como intervenciones de importancia estratégica mayor a pesar de su tamaño extremadamente reducido; eran obras diminutas en relación con la amplitud del territorio que deberían haber incorporado y las dinámicas que deberían haber gatillado. La voluntad de implementarlas suponía visiones de futuro que, alimentadas por la necesidad de afirmar la soberanía nacional, buscaban detonar potenciales ganaderos, acuícolas, forestales o turísticos para incrementar el poblamiento de una frontera aún inhabitada y frágil. Entendiendo el turismo como una actividad más respetuosa del ambiente, la integración longitudinal imaginada más recientemente por las visiones ecologistas también intenta detonar un potencial productivo: posicionar a la Patagonia chilena como destino turístico de clase mundial.

Sin embargo, esto se logra invirtiendo los términos de la ecuación. No se busca incrementar a una exigua población local ni ayudarla sino, por el contrario, se trata de disminuir su presencia, construyendo virginidad y borrando los rastros de su pasado como zona ganadera. En un contexto donde los asuntos geopolíticos fueron desplazados por cuestiones geoeconómicas y de posicionamiento en el turismo global, la resignificación de la región - de última frontera a frontera permanente - 
borró los rastros de la historia bajo la cual fue concebida. Pero imaginar la carretera austral como ruta escénica implica atribuirle el mismo significado de las estrategias de rewilding. Supone, a fin de cuentas, valorarla únicamente por el goce estético que ofrece. Esto deja de lado sus cualidades materiales, las dificultades de su ejecución, el contexto bélico y geoestratégico que motivó su surgimiento y, sobre todo, olvida una historia de incorporación difícil y conflictiva. ARQ

\section{Notas / Notes}

I Entrevista a Ricardo Lagos (Lagos, 2015).

2 Pinochet era profesor de geopolítica y de publicaciones que, aunque criticadas en ciertos ámbitos, demuestran su interés en el tema. (Pinochet, I968).

3 Los proyectos fueron abandonados, quedando vigentes solamente los cruceros a la laguna San Rafael. El canal, luego de la pérdida de unas palas a vapor compradas en Europa (Actas de Cámara de Diputados, I94I) y el Hotel, debido a que después de haber sido arrendado a un concesionario particular, los vapores de los Servicios Marítimos de Ferrocarriles del Estado decidieron no volver a atracar en su muelle (Actas de Camara de Diputados, 1947).

4 Aeródromo que en 1969 fue reemplazado por el aeropuerto internacional actual (Martinic, 2005:378).

5 Una primera idea al respecto se encuentra en el libro de Fernando Veloso Sepúlveda, funcionario del primer gobierno de Ibáñez (Veloso, I932)

\section{Fulvio Rossetti}

$<$ frossett@uc.cl>

Arquitecto Roma 3 (r) Universidad de Chile 2001/2006. Postítulo en Arquitectura del Paisaje, Pontificia Universidad Católica de Chile, 2004. Doctor en Arquitectura y Estudios Urbanos, Pontificia Universidad Católica de Chile, 2018. Trabaja en proyectos de arquitectura, espacios públicos y paisaje y es docente en distintas universidades de Santiago. Ha publicado artículos en distintas revistas, nacionales e internacionales, y en 2009 su primer libro Arquitectura del Paisaje en Chile.

\section{Bibliografía / Bibliography}

A A.vv. La Carretera Austral. El camino más espectacular de Sudamérica. Santiago: Ocho Libros, 2012.

AA.vv. Patagonia chilena $;$ Sin represas! Santiago: Ocho Libros, 2007.

AN DRA DE, L. Comunidad Cooperativa Colonizadora Guaitecas: Plan Guaitecas 1974-I977.Estrategia para el desarrollo del desierto verde. Santiago, Chile: [s.n.], I975.

BRINCK PISENT, G. (Ed.). Las mutaciones de la merluza austral. Historia, cultura y economía política en Isla Toto/Puerto Gala. Santiago: Editorial Cuarto Propio, 20II.

Cámara de Diputados. Actas de la Sesión i8a, extraordinaria, 2 de octubre de i94I.

Cámara de Diputados. Sesión 45a, ordinaria, I6 de septiembre de 1947.

COR Fo. Programa de Desarrollo de la Zona Sur Austral. Santiago: Editorial Corfo, I983.

Ge R S m AnN, R. Chile: 280 Grabados en Cobre. París: Editorial Braun \& Cie, 1932

LAG Os, Ricardo. «El Sueño de Ricardo Lagos». Revista Capital, ıo de diciembre de 2015 .

ma RTinic, M. De la Trapananda al Aysén. Santiago: Pehuén, 2005.
MI LLA R, S. Caballeros del Aire Austral (Cincuenta años de aviación regional): I9I4-I964. Santiago: Editorial Impr. Fuerza Aérea de Chile, I994.

mun ro, G. Carretera Austral, integración de Chile. Santiago: Ediciones Servicios Promocionales, 1982

Mun ro, G. Los Ecos del Silencio, Carretera Austral. Santiago: Ediciones y Publicidad, I989.

PINochet. A. Geopolítica. Diferentes etapas para el estudio geopolítico de los estados. Santiago: Instituto Geográfico Militar, I968.

polloni, A. «Relación de la Carretera Austral con el Poblamiento de la

Patagonia Occidental». Revista Chilena de Historia y Geografía, I54 (I986).

Pollon I, A. Reportaje Geopolítico de la Carretera Austral. Santiago: Guillermo Krum S., I982.

RIED, A. «Un paraíso desconocido», En Viaje 74 (diciembre, I939).

SE R NAT U R. Carretera Austral Presidente Pinochet: The Austral Road. Santiago: Editorial SERNATUR, I987.

SHIGERU, S. Review of ecological researches on Pacific Salmon: introduction into the Aysén region, southern Chile. Tokio: Japan International Cooperation Agency, I986.

ve loso, F. La Provincia de Aisén. Historia, Formación y Desarrollo de las Regiones que Forman la Provincia Actual de Aisén, 1932. 